\title{
Highly active organosulfonic aryl-silica nanoparticles as efficient catalysts for biomass derived biodiesel and fuel additives
}

\author{
Andreia F. Peixoto $^{\text {a,*, }}$ Mohamed M.A. Soliman $^{\mathrm{a}, \mathrm{b}}$, Tânia V. Pinto ${ }^{\mathrm{a}}$, Sónia M. Silva ${ }^{\mathrm{a}}$, \\ Paula Costa $^{\mathrm{a}}$, Elisabete C.B.A. Alegria ${ }^{\mathrm{b}}$, Cristina Freire ${ }^{\mathrm{a}}$ \\ ${ }^{a}$ LAQV-REQUIMTE, Departamento de Química e Bioquímica, Faculdade de Ciências, Universidade Do Porto, Rua Do Campo Alegre s/n, $4169-007$ Porto, Portugal \\ b Área Departamental de Engenharia Química, ISEL, Instituto Politécnico de Lisboa, 1959-007 Lisboa, Portugal
}

\section{A R T I C L E I N F O}

\section{Keywords:}

Sulfonic acid catalysts

Silica nanoparticles

Free fatty acids

Levulinic acid

Furfural

Biodiesel

Fuel additives

\begin{abstract}
A B S T R A C T
Post-grafting methodologies were used to prepare aryl-organosulfonic acid functionalized silica nanoparticles $\left(\mathrm{SO}_{3} \mathrm{H}\right.$-aryl-SiO$\left.{ }_{2} \mathrm{NPs}\right)$ as highly active heterogeneous acid catalysts for catalytic esterification of free fatty acids (FFA) and levulinic acid (LA), and aldol condensation of furfural with 3-methylfuran, well known renewable feedstocks for biodiesel and fuel additives production. The chemical and structural characterization of the $\mathrm{SO}_{3} \mathrm{H}$ aryl- $\mathrm{SiO}_{2} \mathrm{NPs}$ confirmed the success of the functionalization. Complete conversion for all FFA was observed using $\mathrm{SO}_{3} \mathrm{H}$-aryl-SiO${ }_{2} \mathrm{NPs}$ after $2 \mathrm{~h}$ of reaction. $\mathrm{SiO}_{2} \mathrm{NPS}$ CSPTMS showed to be the most active and stable catalyst with no significant loss of activity in the first 5 cycles. In the LA esterification in the presence of an alcohol, complete conversion and selectivity and high reusability were observed (e.g., 83.2\% yield after 10 cycles in the presence of 1-propanol, $\mathrm{SiO}_{2} \mathrm{NPs} 10 \_\mathrm{CSPTMS}$, at $120^{\circ} \mathrm{C}$ and $2 \mathrm{~h}$ reaction). Finally, aldol condensation of furfural and 3-methylfuran had been performed using $\mathrm{SiO}_{2} \mathrm{NPs}_{-} \mathrm{CSPTMS}$ catalysts with almost $100 \%$ yield after $10 \mathrm{~min}$ at $65^{\circ} \mathrm{C}$, high stability and reusability for 7 catalytic cycles.

In general, the prepared $\mathrm{SO}_{3} \mathrm{H}$-aryl-SiO${ }_{2} \mathrm{NPs}$ have demonstrated promising catalytic performance for transformation of biomass-derived feedstocks into biodiesel and fuel additives.
\end{abstract}

\section{Introduction}

The development of new technologies for producing energy and chemicals from biomass, the most abundant and renewable carbon source in the world, has become an important area of research.

Acid-catalyzed hydrolysis, esterification, transesterification, acetylation and condensation are essential processes in the valorization chain of biomass (or biomass components) for food, fuel and chemical industries. Esterification of free fatty acids (FFA) in the presence of an alcohol is an important reaction to transform low grade and cheap feedstock (such as waste oil or grease) generally with high levels of FFA into free fatty acid methyl ester (FAME) for biodiesel production [1-4].

Sugars can be transformed into platform molecules, levulinic acid (LA) is a precious intermediate for the synthesis of several valuable chemicals, including $\gamma$-valerolactone, angelica lactone, ketals, diphenolic acid and alkyl levulinate esters (ALE), which have been used as flavoring and fragrances, solvents, pharmaceuticals, and plasticizers and building blocks in organic synthesis [5,6]. ALE also exhibit similar properties to biodiesel including low toxicity, high lubricity, flash point stability and moderate flow properties under low temperature conditions, making them special molecules for cold flow improvers in biodiesel and as oxygenate additives for fuels gasoline and diesel $[7,8]$. Methyl levulinate can be used as a gasoline additive, while the longer chain alkyl levulinates are potential diesel and biodiesel additives due to their higher solubility in aromatics-rich fuels [9].

During the last decades several heterogeneous catalysts have been employed in esterification (FFA and LA) reactions including zeolites [10, $11]$, acid polymers and resins [12,13] and sulfonic acid functionalized mesoporous silicas [14-17]. Among those, silica-supported materials have received much attention due to their high surface area, tunable porosity/surfaces, high mechanical, thermal stability and easy functionalization $[18,19]$. In particular, mesoporous silicas with alkyl or aryl-sulfonic acids have been widely used in esterification/transesterification of FFA [20-27] and more recently in esterification of LA in the presence of different alcohols. Melero et al. [14] prepared aryl and propyl- $\mathrm{SO}_{3} \mathrm{H}$ functionalized mesostructured silica (SBA-15) and used it

\footnotetext{
* Corresponding author.

E-mail address: andreia.peixoto@fc.up.pt (A.F. Peixoto).
} 


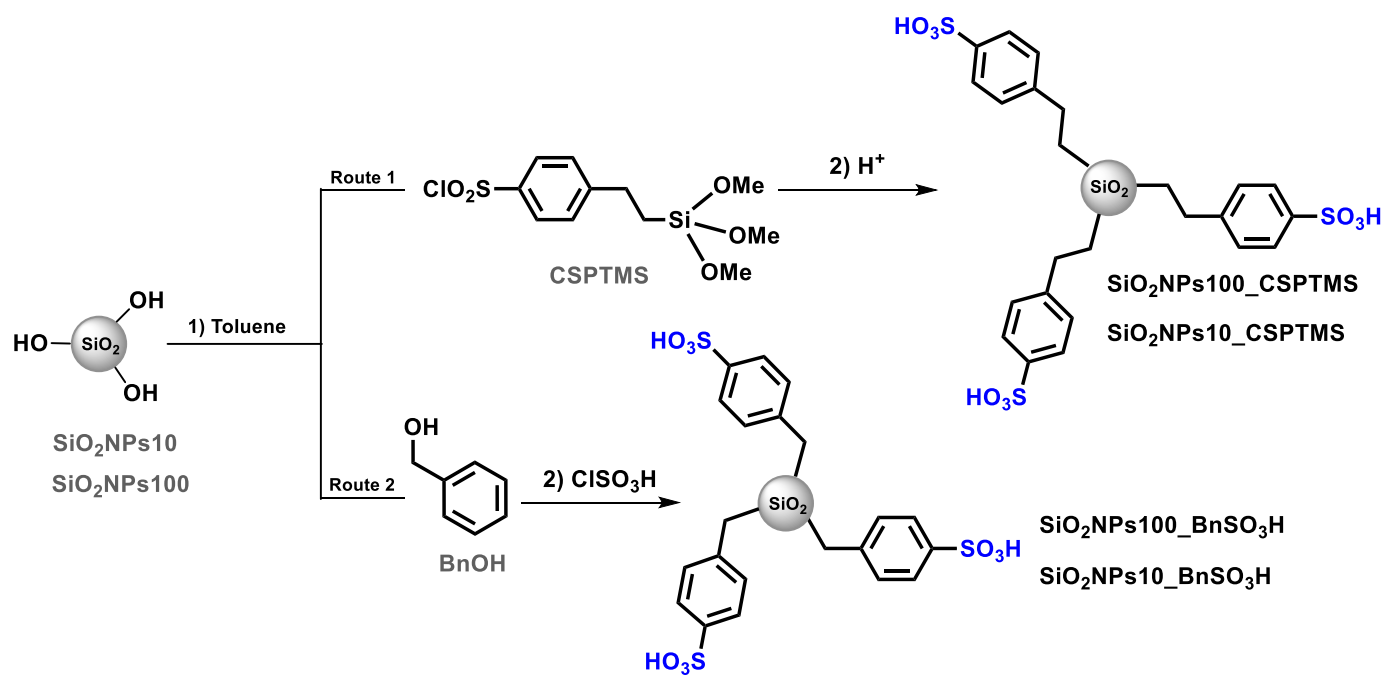

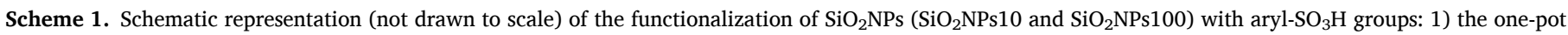

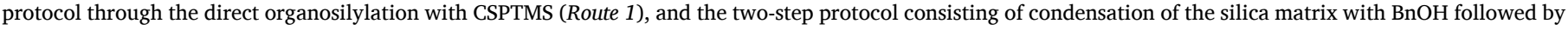
chlorosulfonation of the aromatic ring with $\mathrm{ClSO}_{3} \mathrm{H}$ (Route 2).

in the esterification reaction of LA in the presence of ethanol. The author benchmarked the as-prepared catalysts with sulfonic acid-based commercial solid catalysts. $\mathrm{Pr}_{-} \mathrm{SO}_{3} \mathrm{H}-\mathrm{SBA}-15$ showed to be the most active reaching almost $95.8 \%$ conversion to ethyl levulinate using optimized conditions (obtained by factorial design), ethanol/LA ratio of 4.9/1 and temperature of $117^{\circ} \mathrm{C}$, during $2 \mathrm{~h}$ reaction. Using the same conditions, the authors were able to prepare the butyl levulinate with $\sim 75 \%$ of LA conversion after $4 \mathrm{~h}$. Ramli et al. [17] performed the LA esterification with methanol, ethanol and 1-butanol yielding the levulinate esters with 67,54 and $45 \%$ yield, respectively, using sulphated silica at mild reaction conditions $\left(75^{\circ} \mathrm{C}\right)$.

Furfural a natural precursor derived from biomass (e.g. catalytic hydration of sugars and hemicellulose) has been emphasised as an important building block for value added chemicals and versatile fuel additives [28-31]. Carbon-carbon bond formation designed for petroleum-derived diesel and jet-fuel through furfural condensation reactions is nowadays a promising research topic. Previous studies reported the condensation reaction furfural and 2-methylfuran using heterogeneous catalysts [32,33]. Among the solid-acid catalysts investigated by Li et al. [30], Nafion-212 resin exhibited the highest activity and stability for product 5,5'-bis(2-methylfuranyl)fur-an-2-ylmethane (MFUR) as result of 2-methylfuran (2-MF) and furfural (FUR) condensation. Bell et al. [33] used a silica-bound alkyl sulfonic acid catalyst as active catalysts to promote carbon-carbon bond formation of biomass-derived carbonyl compounds with furfural and 2-methylfuran and observed similar activity and selectivity than those observed with homogeneous acid catalyst. Recently Gil Seo et al. [31] synthesized NP, MCM-41, SBA-15, and KCC-1 supported sulfonic acid-based catalysts by a post-grafting methodology. The catalyst $\mathrm{KCC}-1 \mathrm{SO}_{3} \mathrm{H}$ with high acid density and active site accessibility showed excellent conversion and selectivity to MFUR.

In our previous studies organosulfonic-functionalized propyl- and aryl-silica nanoparticles $\left(\mathrm{SiO}_{2} \mathrm{NPs}\right.$, with particles size of $\sim 100 \mathrm{~nm}$ ) were prepared from organosilane post-grafting methodologies including the catalyst prepared with the organosilane 2-(4-chlorosulfonylphenyl)ethyltrimethoxysilane, CSPTMS, which presented the best catalytic activity for the esterification reaction of linoleic acid [34]. In this work, the study was extended to distinct nano-sized $\mathrm{SiO}_{2} \mathrm{NPs}(10 \mathrm{~nm})$ and different sulfonic acid aryl groups functionalization methodologies to prepare efficient and robust heterogeneous acid catalysts. The catalysts were successfully used in the esterification reaction of different size chain carboxylic acids (lauric, palmitic, oleic, linoleic and stearic acids), in the presence of methanol. Moreover, the more active catalysts were also tested for the esterification of LA, in the presence of 1-butanol and 1-propanol and in condensation reaction of FUR and MF as a potential strategy to prepare biofuels and fuel additives.

\section{Experimental section}

\subsection{Materials, reagents and solvents}

All reagents and solvents were used as received without further purification. Anhydrous toluene (99.8\%), lauric acid (>98\%), levulinic acid (98\%), oleic acid (95\%), stearic acid (95\%) and tetradecane ( $\geq 99 \%$ ) and benzyl alcohol were purchased from Sigma-Aldrich. 2-(4Chlorosulfonylphenyl)ethyltrimethoxysilane (CSPTMS, $50 \mathrm{wt} \%$ in methylene chloride) was acquired from ABCR GmbH. Chlorosulfonic acid $\left(\mathrm{ClSO}_{3} \mathrm{H}, \geq 97 \%\right)$ and palmitic acid $(90 \%)$ were supplied by Fluka. 1-Butanol and 1-propanol (for analysis) were purchased from Merck, and methanol (99.9\%) and sulfuric acid $\left(\mathrm{H}_{2} \mathrm{SO}_{4}, 95 \%\right.$, analytical grade) by Fisher Chemical.

Commercial ORGANOSILICASOL ${ }^{\mathrm{TM}}$ MT-ST, denoted as $\mathrm{SiO}_{2} \mathrm{NPs} 10$, and SNOWTEX ${ }^{\circledR}$ ST-ZL, denoted as $\mathrm{SiO}_{2} \mathrm{NPs} 100$, colloidal suspensions of $\mathrm{SiO}_{2} \mathrm{NPs}$ in methanol (30 wt\%) and water (40 wt\%), with particle sizes around 10-15 and 70-100 nm, respectively, were kindly provided by Nissan Chemical America Corporation (Houston, TX, USA).

\subsection{Preparation of $\mathrm{SO}_{3} \mathrm{H}$-aryl-SiO ${ }_{2} \mathrm{NPS}$}

Two nano-sized silica, $\mathrm{SiO}_{2} \mathrm{NPs} 10$ and $\mathrm{SiO}_{2} \mathrm{NPs} 100$, were functionalized with organosulfonic acid aryl groups using different post-grafting methodologies adapted from the literature [34], Scheme 1: 1) direct organosilylation with a chlorosulfonylphenylethyl - organosilane (CSPTMS) (Route 1), and 2) benzyl alcohol condensation followed by (ii) chlorosulfonation (Route 2). Before the organo-functionalization procedure, the colloidal silica suspensions were evaporated under reduced pressure and then dried at $120^{\circ} \mathrm{C}$ overnight, under vacuum, to remove any physisorbed solvent. Afterwards, the $\mathrm{SiO}_{2} \mathrm{NPs}(2.0 \mathrm{~g})$ were refluxed under stirring for $24 \mathrm{~h}$ with CSPTMS (1.2 mmol) or $\mathrm{BnOH}(96.6$ $\mathrm{mmol}$ ) in anhydrous toluene and under nitrogen atmosphere. Then, the solids were separated by centrifugation, washed with toluene under reflux for $1 \mathrm{~h}$ and dried at $110{ }^{\circ} \mathrm{C}$ overnight. Subsequently, the chlorosulfonyl groups of the $\mathrm{SiO}_{2}$ NPs_CSPTMS samples were hydrolyzed to sulfonic acid counterparts under acidic conditions (Scheme 1, route 1, 
step 2) [34], while the introduction of $-\mathrm{SO}_{3} \mathrm{H}$ groups into the $\mathrm{SiO}_{2} \mathrm{NPs}_{-} \mathrm{BnOH}$ nanomaterials was performed by aromatic ring chlorosulfonation with $\mathrm{ClSO}_{3} \mathrm{H}$ (Scheme 1, route 2, respectively, step 2) [20, 34].

\subsection{Material characterization}

Elemental analysis (EA) of carbon and sulfur were performed on a Leco CHNS- 932, at "Unidad de Análisis Elemental" Universidade de Santiago de Campostela, Spain.

X-ray photoelectron spectroscopy (XPS) was performed at "Centro de Materiais da Universidade do Porto" (CEMUP), Portugal, using a Kratos AXIS Ultra HSA, with VISION software. The analysis was carried out with a monochromatic $\mathrm{Al} \mathrm{K} \alpha$ X-ray source (1486.7 eV), operating at 15 $\mathrm{kV}(90 \mathrm{~W})$, in FAT mode (Fixed Analyzer Transmission), with a pass energy of $40 \mathrm{eV}$ for regions ROI and $80 \mathrm{eV}$ for survey. The powdered samples were pressed into pellets prior to the XPS studies. Data acquisition was performed with a pressure lower than $1 \times 10^{-6} \mathrm{~Pa}$, and a charge neutralization system was used. To correct possible deviations caused by electric charge of the samples, the calibration of the binding energies (BE) was performed using the $\mathrm{C} 1 \mathrm{~s}$ peak at $284.6 \mathrm{eV}(\mathrm{C}-\mathrm{H} / \mathrm{C}-\mathrm{C})$ as internal reference. High resolution $\mathrm{C} 1 \mathrm{~s}, \mathrm{O} 1 \mathrm{~s}, \mathrm{Si} 2 \mathrm{p}$, and $\mathrm{S} 2 \mathrm{p}$ corelevel spectra were analyzed with CasaXPS (Casa Software). For curve fitting of the core-level spectra, a Gaussian/Lorentzian product function peak shape model $(G / L=30)$ was used in combination with a Shirley background.

Fourier transform infrared spectroscopy spectra of all nanomaterials were recorded on a Jasco FT/IR-460 Plus spectrophotometer in the range of $4000-400 \mathrm{~cm}^{-1}$, using a resolution of $4 \mathrm{~cm}^{-1}$ and $32 \mathrm{scans}$; the spectra were obtained in $\mathrm{KBr}$ pellets (Aldrich, FTIR spectroscopic grade) containing $0.2-0.4 \mathrm{wt} \%$ of nanomaterials.

Potentiometric measurements were carried out using $2 \mathrm{~mol} \mathrm{dm}^{-3}$ $\mathrm{NaCl}$ as a cation-exchange agent. $50 \mathrm{~mL}$ of $\mathrm{NaCl}$ solution was maintained in contact with the solid materials $(50 \mathrm{mg}$ ) at room temperature for $24 \mathrm{~h}$ under stirring. The suspension was separated by filtration. The final solution was titrated with $0.04 \mathrm{M} \mathrm{NaOH}$ solution to determine the loading of acid sites on the $\mathrm{SO}_{3} \mathrm{H}$-aryl- $\mathrm{SiO}_{2} \mathrm{NPs}$.

\subsection{Catalytic reactions}

\subsubsection{Esterification reactions of FFA}

The esterification reaction was carried out in a round-bottom flask $\left(25 \mathrm{~cm}^{3}\right)$ fitted with a cooling condenser and a heating oil bath. The correspondent carboxylic acid (lauric acid, linoleic acid, oleic acid, palmitic acid, stearic acid) $(2 \mathrm{~g})$ and methanol $\left(8.67 \mathrm{~cm}^{3}\right)$ were heated at $120{ }^{\circ} \mathrm{C}$, then $10 \mathrm{wt} \%$ of the catalyst $(0.2 \mathrm{~g})$ was added and the reaction mixture was stirred for $2 \mathrm{~h}$. The reaction was followed by gas chromatography (Bruker 430-GC using DB5 column with ramp temperature program: $150{ }^{\circ} \mathrm{C}$ (zero min), $5{ }^{\circ} \mathrm{C} \min ^{-1}$ (ramp), $200{ }^{\circ} \mathrm{C}(3 \mathrm{~min}), 20^{\circ} \mathrm{C}$ $\mathrm{min}^{-1}$ (ramp), $250{ }^{\circ} \mathrm{C}$ ( $3 \mathrm{~min}$ ). The FAME yield (\%) was determined by equation (1) using peak areas of the carboxylic acid ( $\left.\mathrm{A}_{\text {substrate }}\right)$ and the respective methyl ester $\left(A_{\text {product }}\right)$ in the GC chromatogram analysis, after area normalization:

$\% Y=\frac{A_{\text {product }}}{A_{\text {subatrate }}+A_{\text {product }}} \times 100$

The catalysts were reused for 6 cycles for each FFA studied. In the catalytic reaction using the parent $\mathrm{SiO}_{2} \mathrm{NPs}$ negligible substrate conversion was observed.

\subsubsection{Esterification reactions of $L A$}

The esterification reactions of LA with 1-butanol or 1-propanol were carried out in a stirred batch reflux system. Typically, a $25 \mathrm{~mL}$ roundbottom flask was charged with LA and 1-butanol (or 1-propanol); the reagent amounts were calculated according to the desired molar ratio for each reaction (1:6 for LA and alcohol). Then, the internal standard
Table 1

Carbon and sulfur contents of the parent and $\mathrm{SO}_{3} \mathrm{H}$-aryl- $\mathrm{SiO}_{2} \mathrm{NPs}$ obtained by EA and XPS, and acid capacity.

\begin{tabular}{|c|c|c|c|c|}
\hline \multirow[t]{2}{*}{ Material } & \multicolumn{2}{|c|}{$\begin{array}{l}\text { EA analysis } \\
\left(\mathrm{mmol} \mathrm{g}^{-1}\right)\end{array}$} & \multirow{2}{*}{$\begin{array}{l}\text { XPS analysis } \\
\left(\mathrm{mmol} \mathrm{g}^{-1}\right)\end{array}$} & \multirow[t]{2}{*}{$\begin{array}{l}\text { Acid capacity ( } \mathrm{mmol} \\
\left.\mathrm{H}^{+} \mathrm{g}^{-1}\right)^{\mathrm{b}}\end{array}$} \\
\hline & $\mathrm{C}$ & S & & \\
\hline $\mathrm{SiO}_{2} \mathrm{NPs} 100$ & $<0.6$ & - & - & - \\
\hline $\mathrm{SiO}_{2} \mathrm{NPs}_{100 \_C S P T M S}$ & 10.2 & 1.2 & 1.2 & 1.9 \\
\hline $\mathrm{SiO}_{2} \mathrm{NPs} 100 \mathrm{BnSO}_{3} \mathrm{H}$ & 0.6 & 1.5 & 2.3 & 3.8 \\
\hline $\mathrm{SiO}_{2} \mathrm{NPs} 10$ & $<0.6$ & - & - & - \\
\hline $\mathrm{SiO}_{2} \mathrm{NPs} 10 \_\mathrm{CSPTMS}$ & 10.0 & 1.2 & 1.0 & 1.3 \\
\hline $\mathrm{SiO}_{2} \mathrm{NPs}_{10} \mathrm{BnSO}_{3} \mathrm{H}$ & 4.4 & 3.5 & 4.4 & 6.8 \\
\hline
\end{tabular}

${ }^{\text {a }}$ Determined by the areas of the respective bands in the high-resolution XPS spectra.

b Calculated by potentiometric titration.

tetradecane $(150 \mu \mathrm{L})$ and the catalyst (10 wt $\%$ to LA) were added, and the system was heated up to $120^{\circ} \mathrm{C}$. The reaction was carried out for $2 \mathrm{~h}$ and followed by gas chromatography (Thermo Scientific Trace 1300 GC using TRB- 5 column with ramp temperature program: $50{ }^{\circ} \mathrm{C}(2 \mathrm{~min})$, $50{ }^{\circ} \mathrm{C} \mathrm{min}-1$ (ramp), $200{ }^{\circ} \mathrm{C}(2 \mathrm{~min}), 20{ }^{\circ} \mathrm{C} \min ^{-1}$ (ramp), $280{ }^{\circ} \mathrm{C}(8$ $\min )$. The LA ester yield $(\% \mathrm{Y})$ was determined according to the following equation (1). To evaluate the stability and reusability of the catalyst, the used catalyst was recovered after each catalytic washed and dried at $100{ }^{\circ} \mathrm{C}$ overnight. Afterwards, the recovered catalyst was reused in new LA esterification reactions until 10 cycles.

\subsubsection{Aldol condensation reaction of furfural}

A reaction mixture of furfural $(0.385 \mathrm{~g}, 0.33 \mathrm{~mL}, 4 \mathrm{mmol})$ and 2 methylfuran $(0.725 \mathrm{~g}, 0.796 \mathrm{~mL}, 8.8 \mathrm{mmol})$ were placed in a capped glass vessel, and $\mathrm{SiO}_{2} \mathrm{NPs}_{-} \mathrm{CSPTMS}$ catalyst $(0.2 \mathrm{mmol}, 5 \mathrm{~mol} \%)$ was added. The reaction mixture was left at the pre-adjusted temperature $65{ }^{\circ} \mathrm{C}$ for $2 \mathrm{~h}$. Afterwards the solid catalyst was separated from the reaction mixture by filtration and the isolated solution was dried over anhydrous $\mathrm{Na}_{2} \mathrm{SO}_{4}$, where upon the crude product was analyzed by ${ }^{1} \mathrm{H}$ $\mathrm{NMR}$ using $\mathrm{CDCl}_{3}$. Further, the reaction progress was followed by taking aliquot samples and diluted by $\mathrm{CH}_{2} \mathrm{Cl}_{2}$ before $\mathrm{GC}$ injection.

In order to perform the catalyst recycling experiments, the catalyst was separated, by mean of filtration kit and washed with ethyl acetate $(3 \times 3 \mathrm{~mL})$ and diethyl ether $(1 \times 3 \mathrm{~mL})$ and acetone $(1 \times 3 \mathrm{~mL})$ and finally dried before being reused.

\section{Results and discussion}

\subsection{Chemical and structural characterization}

The parent $\mathrm{SiO}_{2} \mathrm{NPs}, \mathrm{SiO}_{2} \mathrm{NPs}_{-} 10$ and $\mathrm{SiO}_{2} \mathrm{NPs}_{-} 100$, were exhaustively characterized in previous reports by several techniques (SEM, TEM and FTIR) [34-36]. The TEM and SEM micrographs of the $\mathrm{SiO}_{2} \mathrm{NPs}_{-} 10$ and $\mathrm{SiO}_{2} \mathrm{NPs}_{-} 100$, respectively, revealed uniform spheres with an average particle size of $123 \pm 7 \mathrm{~nm}$ and $15 \pm 3 \mathrm{~nm}$, and narrow size distributions $[35,36]$. Upon organosulfonic-functionalization of the $\mathrm{SiO}_{2} \mathrm{NPs}_{-} 100$ with different alkyl and aryl-organosilanes no significant morphological changes were observed [34].

The chemical composition of the parent and $\mathrm{SO}_{3} \mathrm{H}$-aryl-SiO ${ }_{2} \mathrm{NPs}$ was determined by elemental analysis ( $\mathrm{S}$ and $\mathrm{C}$ by EA) and XPS ( $\mathrm{S}$ surface content); the results are displayed in Table 1 . The increase of carbon content and the presence of sulfur on the functionalized $\mathrm{SiO}_{2} \mathrm{NPs}$ corroborates the success of both procedures (direct organosulfonicfunctionalization and two-step condensation followed by sulfonation). However, a significant increase in carbon content was detected on the $\mathrm{SiO}_{2} \mathrm{NPs}_{-} \mathrm{CSPTMS}$ samples $\left(\geq 10.0 \mathrm{mmol} \mathrm{g}^{-1}\right)$ suggesting that the direct organosilylation of the $\mathrm{SiO}_{2} \mathrm{NPs}$ allowed the incorporation of the organosilane with success for both $\mathrm{SiO}_{2} \mathrm{NPs}(10$ and $100 \mathrm{~nm})$. These results are also corroborated by a similar amount of bulk $\mathrm{S}$ content observed for $\mathrm{SiO}_{2} \mathrm{NP}_{-} 10_{-} \mathrm{CSPTMS}$ and $\mathrm{SiO}_{2} \mathrm{NP}_{-} 100 \_\mathrm{CSPTMS}$, indicating that the 

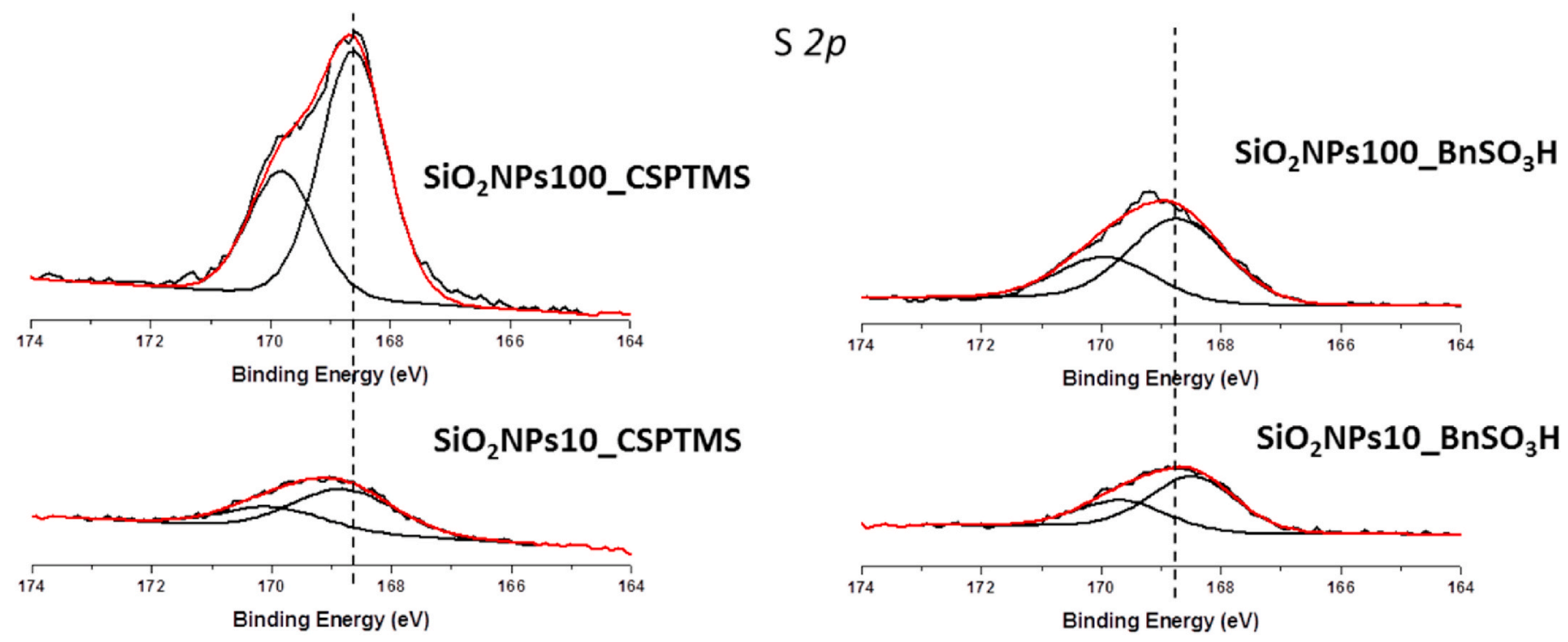

Fig. 1. Deconvoluted XPS high-resolution spectra of $\mathrm{SiO}_{2} \mathrm{NPs} 100_{-} \mathrm{CSPTMS}, \mathrm{SiO}_{2} \mathrm{NPs}_{100} \mathrm{BnSO}_{3} \mathrm{H}, \mathrm{SiO}_{2} \mathrm{NPs}_{10} \mathrm{CSPTMS}_{-}$and $\mathrm{SiO}_{2} \mathrm{NPs}_{10} \mathrm{BnSO}_{3} \mathrm{H}$ in the $\mathrm{S} 2 \mathrm{p}$ region. The overall simulated spectra are represented by red lines. (For interpretation of the references to colour in this figure legend, the reader is referred to the Web version of this article.)
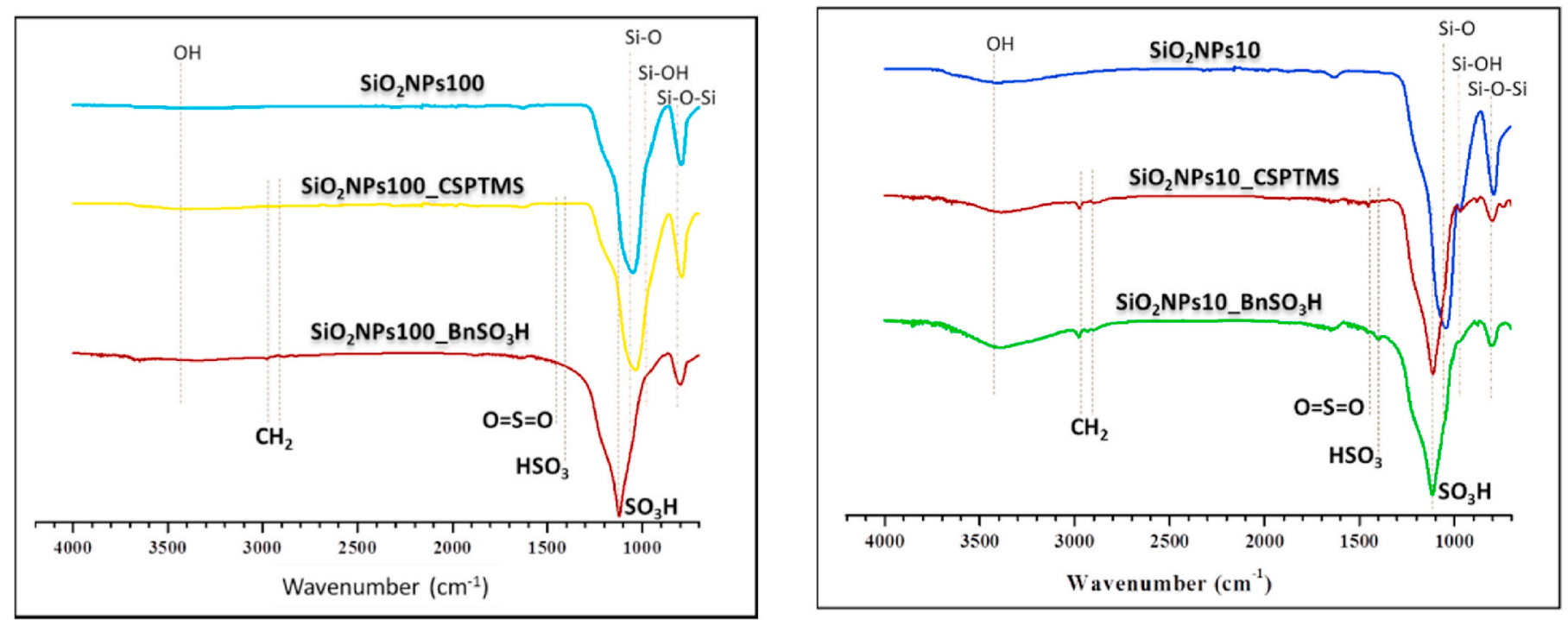

Fig. 2. FTIR spectra in the $4000-400 \mathrm{~cm}^{-1}$ region of: a) $\mathrm{SiO}_{2} \mathrm{NPs} 10, \mathrm{SiO}_{2} \mathrm{NPs}_{2}{ }_{-} \mathrm{CSPTMS}$ and $\mathrm{SiO}_{2} \mathrm{NPs}_{2} \mathrm{Bn}_{-} \mathrm{BnO}_{3} \mathrm{H}$; and b) $\mathrm{SiO}_{2} \mathrm{NPs}_{100}$, $\mathrm{SiO}_{2} \mathrm{NPs} 100 \_\mathrm{CSPTMS}$ and $\mathrm{SiO}_{2} \mathrm{NPs}_{100} \mathrm{BnSO}_{3} \mathrm{H}$.

particle size is not critical in the sulfonic acid groups functionalization. The $\mathrm{SiO}_{2} \mathrm{NPs}_{-} \mathrm{BnSO}_{3} \mathrm{H}$ exhibit the highest amount of bulk and surface sulfur $\left(\geq 1.5 \mathrm{mmol} \mathrm{g}^{-1}\right)$, which indicates the presence of high amount of $-\mathrm{SO}_{3} \mathrm{H}$ groups. Although the low content of $\mathrm{C}$ observed in EA analysis could be an evidence of benzyl-group lixiviation during the sulfonation treatment and a consequent direct chlorosulfonation on $\mathrm{SiO}_{2} \mathrm{NPs}$. The surface sulfur content observed by XPS is higher than the observed for EA bulk content for $\mathrm{SiO}_{2} \mathrm{NPs} 100$ CSPTMS and both $\mathrm{SiO}_{2} \mathrm{NPs}_{-} \mathrm{BnSO}_{3} \mathrm{H}$ (10 and $100 \mathrm{~nm}$ ) suggesting a prevalence for sulfonic acid groups to covalently bind on the surface of $\mathrm{SiO}_{2} \mathrm{NPs}$. The acid character of the $\mathrm{SO}_{3} \mathrm{H}$-aryl- $\mathrm{SiO}_{2} \mathrm{NPs}$ was measured by potentiometric titration. $\mathrm{SiO}_{2} \mathrm{NPs} 100 \_$CSPTMS presents slightly higher acidity than $\mathrm{SiO}_{2} \mathrm{NPs} 10$ CSPTMS. The benzyl- $\mathrm{SO}_{3} \mathrm{H}$ functionalized $\mathrm{SiO}_{2} \mathrm{NPs}$ present higher acidity than the functionalized $\mathrm{SiO}_{2}$ NPs_CSPTMS in accordance with the amounts of sulfur (bulk and surface) obtained by EA and XPS.

The chemical surface analysis of the $\mathrm{SiO}_{2} \mathrm{NPs}_{-} 10$ and $\mathrm{SiO}_{2} \mathrm{NPs}_{-} 100$ nanomaterials obtained by XPS (Table 1 and Fig. 1 ) reveal the presence of $\mathrm{O}, \mathrm{C}$ and $\mathrm{Si}$ with similar amounts in the surface of both $\mathrm{SiO}_{2} \mathrm{NPs}$ [34]. The functionalization of the $\mathrm{SiO}_{2} \mathrm{NPs}$ with $\mathrm{SO}_{3} \mathrm{H}$-aryl groups leads to the appearance of sulfur (1.8-7.2\%) as well as to the increase of carbon content on the surface (13.2-44.0\%) with the concomitant decrease of oxygen and silicon atomic percentages (39.6-63.5\% and $7.1-22.5 \%$, respectively).

To gain further insights regarding the surface chemical and structural composition of the organosulfonic-functionalized $\mathrm{SiO}_{2} \mathrm{NPs}$, the deconvolution of the $\mathrm{C} 1 \mathrm{~s}, \mathrm{O} 1 \mathrm{~s}, \mathrm{Si} 2 \mathrm{p}$ and $\mathrm{S} 2 \mathrm{p}$ high-resolution spectra were also performed; the core-level binding energies are summarized in Table S1 and the high-resolution XPS spectra in S 2p region is presented in Fig. 1. The high resolution spectra of $\mathrm{C}, \mathrm{O}$ or $\mathrm{Si}$ of the parent $\mathrm{SiO}_{2} \mathrm{NPs}$ and the functionalized $\mathrm{SO}_{3} \mathrm{H}$-aryl- $\mathrm{SiO}_{2} \mathrm{NPs}$ are presented in $\mathrm{Fig}$. $\mathrm{S} 2$ in the Supporting Information. Characteristic bands of oxygen and silicon were detected in the silica frameworks at binding energies (BEs) of 532.6 and $103.0 \mathrm{eV}$ respectively [37]. The high-resolution spectra of functionalized $\mathrm{SO}_{3} \mathrm{H}$-aryl-SiO ${ }_{2} \mathrm{NPs}$ exhibit peaks at 533.5, 103.3 and 169.6-170.1 

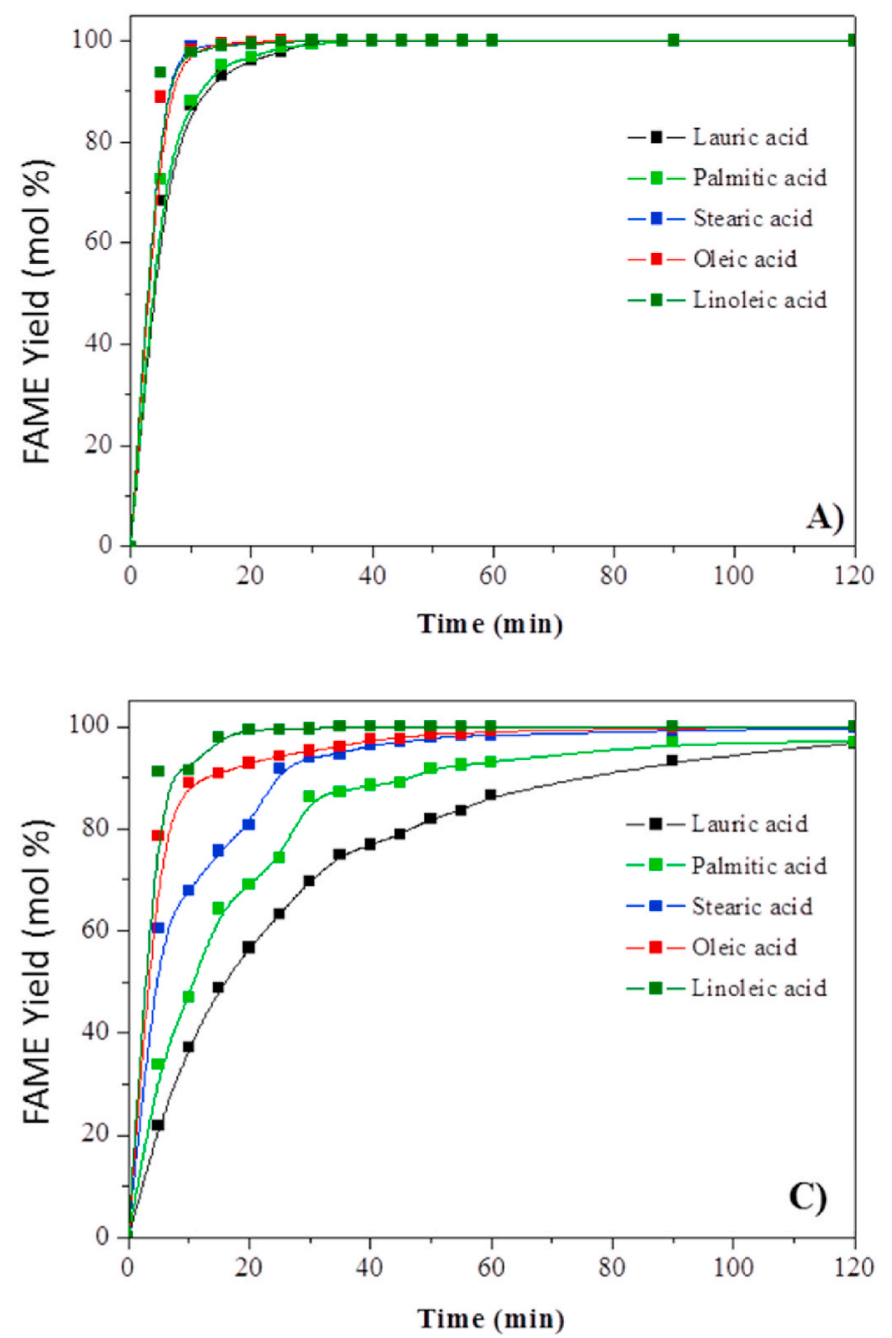

Fig. 3. Yields of FFA methyl esters obtained with $\mathrm{SO}_{3} \mathrm{H}$-aryl- $\mathrm{SiO}_{2} \mathrm{NPs}$, $\mathrm{SiO}_{2} \mathrm{NPs}_{100 \_C S P T M S}$ in methanol at $120^{\circ} \mathrm{C}$.

$\mathrm{eV}$, which are assigned to $\mathrm{O}-\mathrm{C}, \mathrm{Si}-\mathrm{C}$ and $\mathrm{S}-\mathrm{O} / \mathrm{S}=\mathrm{O}$ bonds, respectively, confirming the presence of the organosilane and the $-\mathrm{SO}_{3} \mathrm{H}$ groups, on the surface of the $\mathrm{SiO}_{2} \mathrm{NPs}$ [37-40]. Additionally, the S 2p spectra exhibit an intense band at $\sim 168.6 \mathrm{eV}$ attributed to sulfur in its oxidized form $S^{6+}$.

The organosulfonic-functionalization of the $\mathrm{SiO}_{2} \mathrm{NPs}$ can also be corroborated by FTIR spectroscopy (Fig. 2). The FTIR spectra of the parent $\mathrm{SiO}_{2} \mathrm{NPs}$ and functionalized $\mathrm{SO}_{3} \mathrm{H}$-aryl-SiO${ }_{2} \mathrm{NPs}$, Fig. 2, exhibit the typical bands of the silica framework, such as: $\mathrm{Si}-\mathrm{O}-\mathrm{Si}$ asymmetric stretching $\left(1110 \mathrm{~cm}^{-1}\right.$ with a shoulder around $\left.1220 \mathrm{~cm}^{-1}\right)$ and symmetric stretching $\left(804 \mathrm{~cm}^{-1}\right), \mathrm{Si}-\mathrm{O}$ in-plane stretching of $\mathrm{Si}-\mathrm{OH}$ and $\mathrm{Si}-\mathrm{O}$ - groups $\left(968 \mathrm{~cm}^{-1}\right)$ and $\mathrm{Si}-\mathrm{O}-\mathrm{Si}$ bending $\left(474 \mathrm{~cm}^{-1}\right)$ vibrations [34-36]. The FTIR spectra of the $\mathrm{SO}_{3} \mathrm{H}$-aryl- $\mathrm{SiO}_{2} \mathrm{NPs}$ present additional bands assigned to the aromatic $\mathrm{C}-\mathrm{H}$ stretching $\left(3100-3000 \mathrm{~cm}^{-1}\right), \mathrm{C}-\mathrm{H}$ stretching $\left(2974-2893 \mathrm{~cm}^{-1}\right)$ of $\mathrm{CH}_{2} / \mathrm{CH}_{3}$ groups, and skeletal (1600-1400 $\left.\mathrm{cm}^{-1}\right)$ vibrations [41,42]. Moreover, bands assigned to $\mathrm{C}-\mathrm{SO}_{2}-\mathrm{OH}$ stretching asymmetric (very weak; $1340 \mathrm{~cm}^{-1}$ ) and $\mathrm{S}-\mathrm{O}$ stretching $\left(698 \mathrm{~cm}^{-1}\right)$ vibrations confirm the presence of sulfonic acid groups; although, the bands corresponding to the $\mathrm{C}-\mathrm{SO}_{2}-\mathrm{OH}$ stretching symmetric vibrations are overlapped by the characteristic modes of the silica network $\left(1165-1150 \mathrm{~cm}^{-1}\right)[34,41,43]$.

Additionally, all spectra feature a broad band centered around 3390 $\mathrm{cm}^{-1}$ related with the $\mathrm{O}-\mathrm{H}$ stretching vibrations of hydrogen-bonded surface silanol groups, $\mathrm{SO}_{3} \mathrm{H}$ groups (in the case of $\mathrm{SO}_{3} \mathrm{H}$-aryl$\mathrm{SiO}_{2} \mathrm{NPs}$ ), and physically adsorbed water, and a band at $1643 \mathrm{~cm}^{-1}$
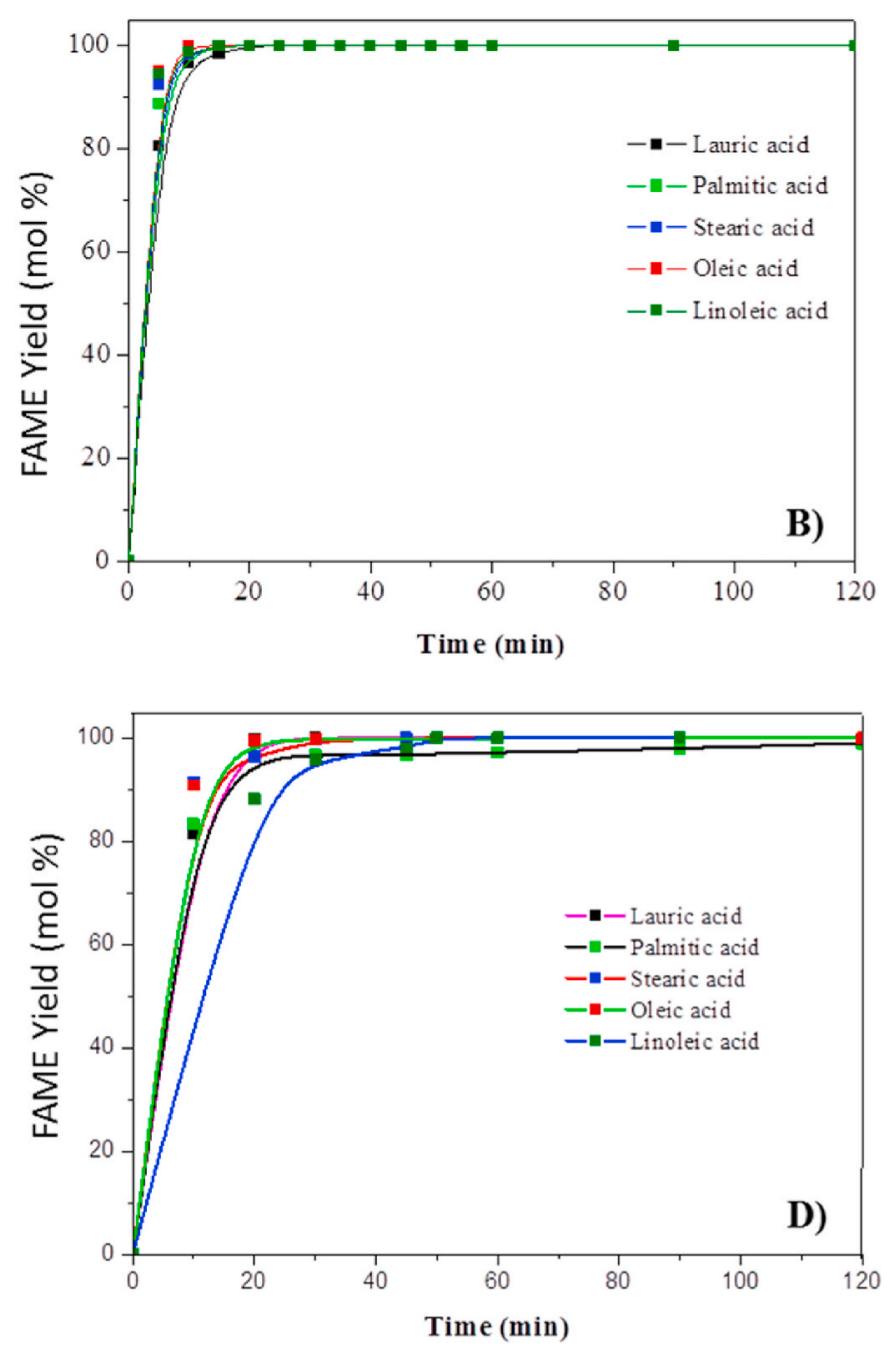

A) $\mathrm{SiO}_{2} \mathrm{NPs}_{100} \mathrm{BnSO}_{3} \mathrm{H}$, B) $\mathrm{SiO}_{2} \mathrm{NPs}_{10} \mathrm{BnSO}_{3} \mathrm{H}$, C) $\mathrm{SiO}_{2} \mathrm{NPs}_{10} \mathrm{CSPTMS} ;$ D) assigned to the $\mathrm{H}-\mathrm{O}-\mathrm{H}$ bending vibrations of adsorbed water [34-37, 41].

\subsection{Catalytic performance in the esterification reaction of FFA}

The catalytic performance of $\mathrm{SiO}_{2} \mathrm{NPs} 100$ CSPTMS was previously described [34] for the esterification of linoleic acid, showing the best activity and stability. In order to evaluate the particle size and functionalization methodology effect on the restriction of the diffusion of long carbon chains (typical of biodiesel types of substrates and products), the as prepared catalysts were applied in the esterification reaction of different size chain carboxylic acids (saturated and unsaturated) such as lauric (LaA, C12), linoleic (LA, C18:2), oleic (OA, C18:1), palmitic (PA, C16) and stearic (SA, C18) acid, in the presence of methanol at $120^{\circ} \mathrm{C}$. Fig. 3 shows the yield evolution $v$ s. reaction time. Also, a blank run (reaction without catalyst) has been performed in the same conditions in order to determine the extension of thermally-driven reactions in which very low yield were obtained (FFA conversions of $\sim 7 \%$ ). High catalytic performances were observed for all the $\mathrm{SO}_{3} \mathrm{H}$-aryl- $\mathrm{SiO}_{2} \mathrm{NPs}$, after $2 \mathrm{~h}$ of reaction, with $100 \%$ yield for lauric, linoleic, oleic, palmitic and stearic methyl esters. Moreover, the $\mathrm{SiO}_{2} \mathrm{NPs}_{-} \mathrm{BnSO}_{3} \mathrm{H}$ functionalized materials showed to be the most efficient catalysts for the esterification reaction of different size chain saturated or unsaturated carboxylic acids, reaching almost $100 \%$ yield in less than $30 \mathrm{~min}$. The same behavior was observed for catalytic system using 


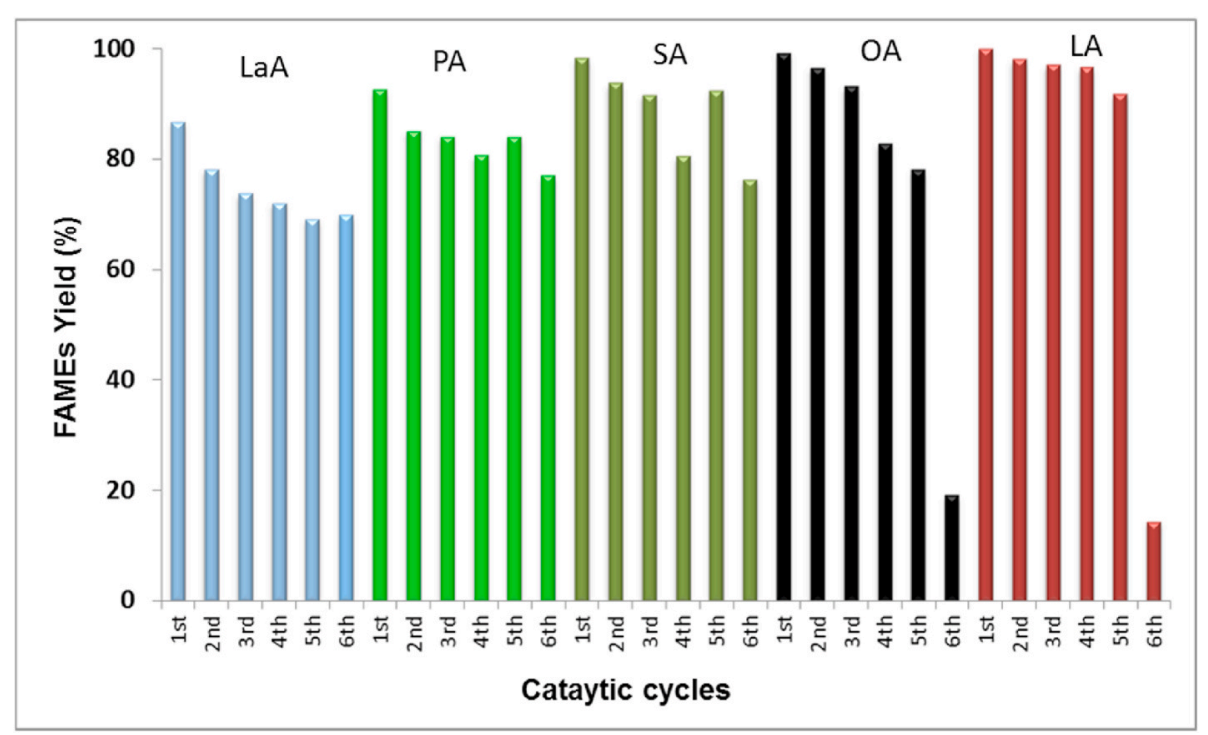

Fig. 4. Reusability of the $\mathrm{SiO}_{2} \mathrm{NPs} 10$ CSPTMS in the first five cycles of catalytic esterification for different size chain (saturated and unsaturated) carboxylic acids.

$\mathrm{SiO}_{2} \mathrm{NPS}_{-} \mathrm{CSPTMS}$ as catalyst, nevertheless the formation of lauric, palmitic and stearic methyl esters showed lower reaction rate until $1 \mathrm{~h}$ indicating for this type of catalysts an induction period is necessary although at the end of the reaction both catalysts showed almost $100 \%$ yield. Also, for $\mathrm{SiO}_{2} \mathrm{NPs} 10$ CSPTMS it is possible to notice that longer aliphatic chains converted faster than the shorter aliphatic chain carboxylic acids (PA-C16 and LaA-C12). This is in accordance with our previous results with halloysite nanotubes and cloisite $\mathrm{Na}^{+}$functionalized with the same organosilane (HNT_CSPTMS) [44] and Cloi_CSPTMS [45], respectively; and also with the mechanism proposed for the use of homogeneous acid catalysts, in which the carboxylic acid reactivity increases with the increase of FFAs carbon chain as a direct consequence of inductive effect increase with chain length. This increases the electron donating ability of the acid favouring protonation of carboxylate oxygen and thereafter the nucleophilic attack by the alcohol. However, some authors observed a decrease in carboxylic acid reactivity with the increasing of FFA alkyl chain length when use heterogeneous catalysts $[46,47]$. The authors also attributed the lower reactivity to diffusion limitation and reduced accessibility of acid sites, although this was not observed using the $\mathrm{SO}_{3} \mathrm{H}$-aryl- $\mathrm{SiO}_{2} \mathrm{NPs}$ presented in this paper showing the potential of these materials to be use as catalysts in esterification of any type of FFA. The effect of particles size $(10$ and $100 \mathrm{~nm})$ is not significant although it is evident that the use of silica nanoparticles with high surface-area resulted in higher yields. This was also recently observed by J. Bordado et al. when micro-structured calcium oxide obtained from natural sources (chicken eggshells) was applied as catalyst for the transesterification of soybean oil. The authors attributed the low yields to the large particles size ( $>500 \mathrm{~nm}$ ) and suggested the use of a supercritical anti-solvent (SAS) micronization technique to reduce the particle size and to allow an increase in surface area with consequent mass transfer limitations reduction resulting in higher catalytic activity and high yields [48].

In terms of activity and stability, the $\mathrm{SiO}_{2} \mathrm{NPs} 10 \_\mathrm{CSPTMS}$ proved to be the most active heterogeneous acid catalyst for the esterification reaction of the linoleic, oleic and stearic acids with $100 \%$ conversion and for palmitic and lauric acids with $93 \%$ and $87 \%$, respectively, using methanol at $120{ }^{\circ} \mathrm{C}$ (Fig. 3) showing the high-performance of this catalyst for long chain fatty acid esterification overcoming the typical diffusion problems of these type of substrates and surpassing the catalytic performance of bulk mesoporous silicas derived from SBA-15 and KIT-6 in FFA esterification of propanoic-C3, hexanoic-C6, lauric-C12 and palmitic acids-C16 [26,34]. The synergetic combination of high surface-area-to-volume-ratio and functional aryl-sulfonic acid groups allowed to achieved also high stability and reusability, key properties for future industrial applications.

The heterogeneous nature of the esterification reactions was proved by the absence of any catalytic activity upon removal of the catalysts from the reaction media after $10 \mathrm{~min}$ of reaction.

The synergetic combination of high surface-area-to-volume-ratio with aryl-sulfonic acid functional groups allowed achieving high reusability for $\mathrm{SiO}_{2} \mathrm{NPs} 10$ CSPTMS, Fig. 4, which can be attributed to an higher stability of organosulfonic acid linked to silica nanoparticles catalyst compared with the remainder catalysts. This catalyst was recovered and reused for five consecutive cycles without significant loss of activity although in the $6^{\text {th }}$ cycle a significant and abrupt loss of activity was observed for oleic and linoleic acids maybe due to a reduction in the reactivity as a consequence of reduced accessibility to acid sites (Fig. 4).

The excellent activity and reusability of $\mathrm{SiO}_{2} \mathrm{NPs} 10$ CSPTMS to convert all the FFA into the corresponding esters allows to assume the potential of this catalyst to be applied in a pre-treatment esterification of feedstocks with high content and diversity of FFA for biodiesel production, since feedstocks could contain different types and amounts of unsaturated or saturated, short and long chain FFA depending on the source [45].<smiles>CC(=O)CCC(=O)O</smiles>

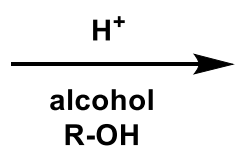<smiles>[R]OC(=O)CCC(C)=O</smiles>

Scheme 2. Esterification reaction of levulinic acid to alkyl levulinate. 

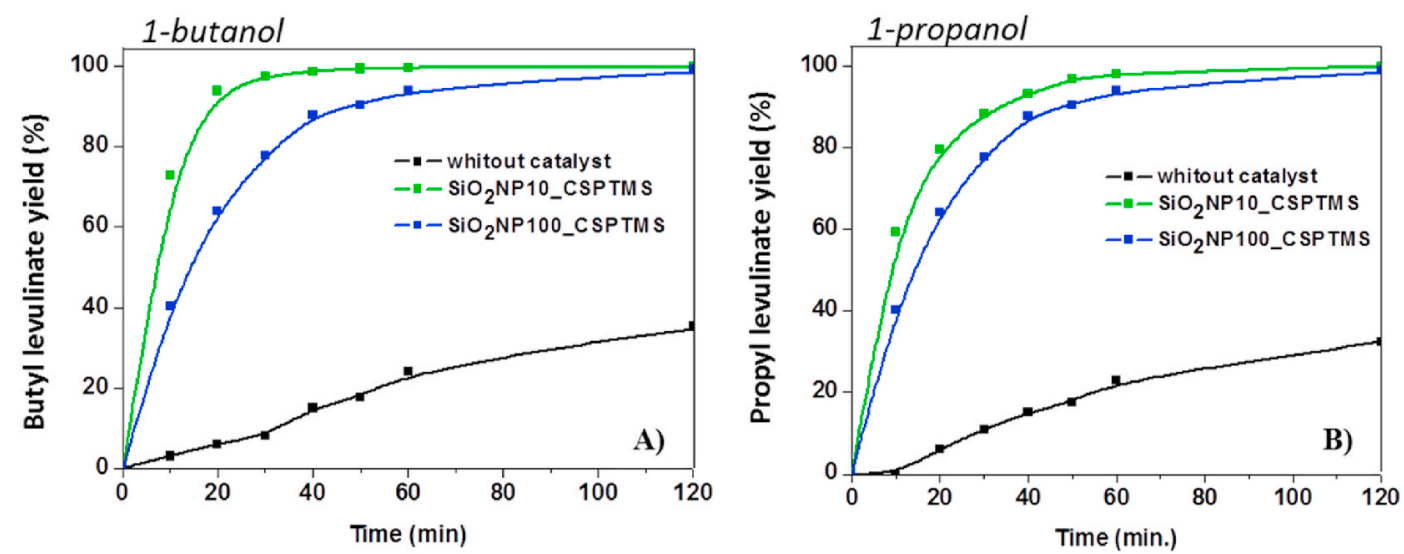

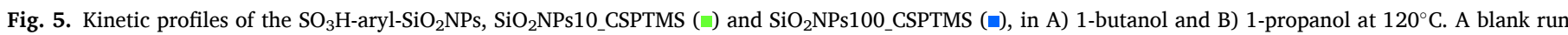
(without catalyst; $\square$ ) was performed in both alcohols at $120^{\circ} \mathrm{C}$.
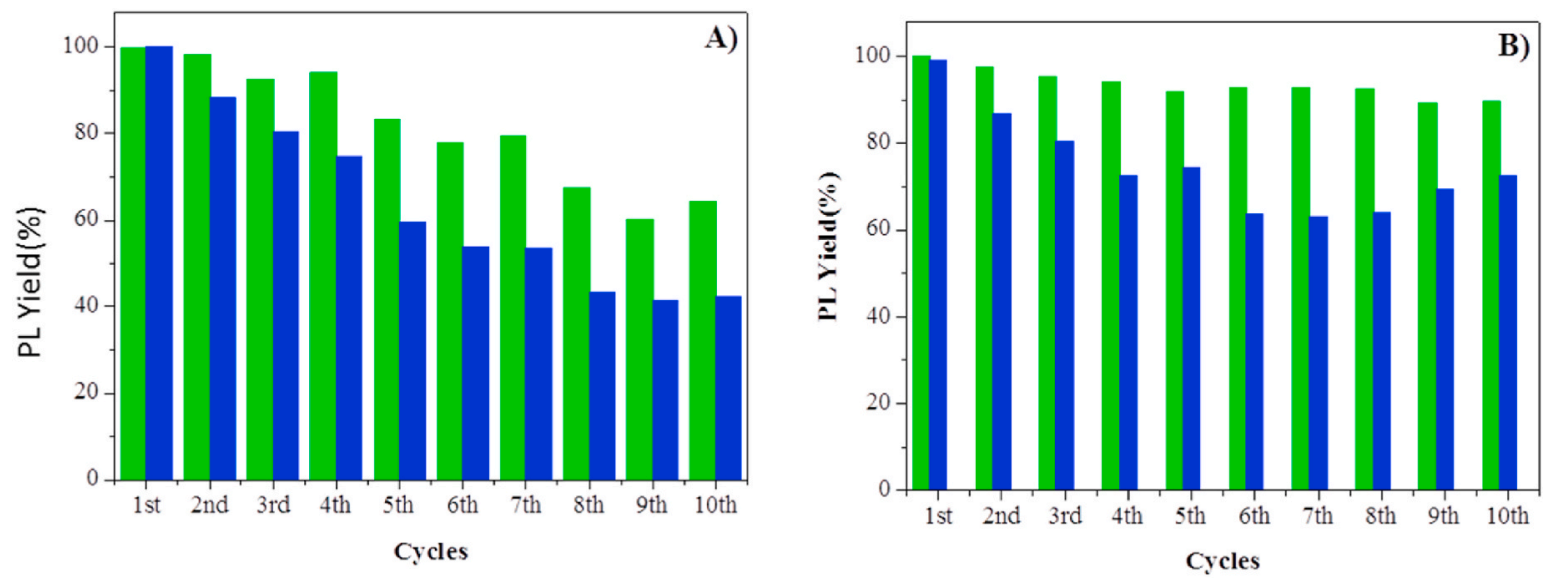

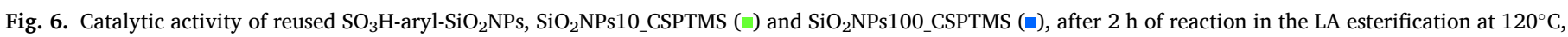
alcohol (1-butanol; A and 1-propanol; B)/LA molar ratio of 6:1 and $10 \mathrm{wt} \%$ of catalyst.

\subsection{Catalytic performance in the esterification reaction of $L A$}

The catalytic performance of the $\mathrm{SiO}_{2}$ NPs10_CSPTMS and $\mathrm{SiO}_{2} \mathrm{NPs}_{100} \mathrm{CSPTMS}$ catalysts was screened for the esterification of LA in presence of 1-butanol and 1-propanol to afford the corresponding alkyl levulinates, was also explored (Scheme 2). The schematic representation of the catalytic kinetic profiles is presented in Fig. 5.

All the catalysts provided almost $100 \%$ conversion after $120 \mathrm{~min}$ for both 1-butanol and 1-propanol alcohols. The catalyst $\mathrm{SiO}_{2} \mathrm{NPs}_{10} \mathrm{CSPTMS}$ showed to be the most active to convert the LA into the corresponding butyl and propyl levulinate (BL, PL) with 97.4 and $88.3 \%$ yield after $30 \mathrm{~min}$ using 1-butanol and 1-propanol, respectively. Benchmarking the catalytic performance of both $\mathrm{SiO}_{2} \mathrm{NPs}_{10}$ CSPTMS and $\mathrm{SiO}_{2} \mathrm{NPs}_{100} \mathrm{CSPTMS}$ for butyl levulinate production it is possible to confirm higher reaction rate for $\mathrm{SiO}_{2} \mathrm{NPs} 10$ _CSPTMS in the first $60 \mathrm{~min}$, although after $120 \mathrm{~min}$ both catalysts are very active and selective to BL. A similar behavior was observed in PL production, although with less pronounced difference. Moreover, the alkyl levulinates were the major/ unique product detected in all cases, and no ethers coming from the intermolecular dehydration of the different alcohols were observed under the tested reaction conditions. In addition, both blank experiments in the absence of any catalyst yielded $\sim 32 \%$ (after $2 \mathrm{~h}$ ) of the respective ester, due to the intrinsic acid character of LA, which can autocatalyze the esterification reaction to some extent [8]. The synthesis of $\mathrm{BL}$ and $\mathrm{PL}$ using this sulfonic acid functionalized $\mathrm{SiO}_{2}$ follows an acid catalyzed mechanism in which the carbonyl oxygen coordinates with acid active site increasing the electrophilicity of carbonyl carbon. The nucleophilic oxygen of the corresponding alcohol attacks the carbonyl carbon to form the oxonium ion and finally the loss of water and consecutive deprotonation allows the formation of EL $[8,17]$. The presence of an acid catalyst is imperative since the catalyst acid sites improve the proton accessibility and the esterification reaction rate as it is possible to see in Fig. 5.

The stability and reusability of the catalysts were evaluated; the results are displayed in Fig. 6. From the recycling studies performed with 1-butanol, Fig. 6A, $\mathrm{SiO}_{2} \mathrm{NPs}_{10}$ CSPTMS exhibited good stability with no significant loss of activity after several cycles under optimized reaction conditions. For instance, the catalytic activity of the $\mathrm{SiO}_{2} \mathrm{NPs}_{10} \mathrm{CSPTMS}$ was maintained above of $83.2 \%$ after five consecutive catalytic cycles, and $64.2 \%$ after 10 cycles. The sequential loss of catalytic activity can be attributed to the surface adsorption of intermediates, which could result in poor acid site accessibility as observed for other sulfonic acid-SiO catalysts $[20,34,49]$. In addition, the presence of water on the catalyst surface can inhibit the catalytic sites of inorganic materials [50]. Acidic and/or hydrophilic metal oxides easily adsorb water on their surface, which is the coproduct of the esterification, preventing the adsorption of other organic molecules. This can severely reduce the activity of the catalyst for consecutive cycles [50]. Comparing with data from literature (Table S1, supplementary information), the catalyst $\mathrm{SiO}_{2}$ NPs10_CSPTMS allowed an improvement of up to $100 \%$ for BL and PL products in shorter reaction time (40-60 min), only comparable with our previous results obtained in the esterification of LA and n-butanol 


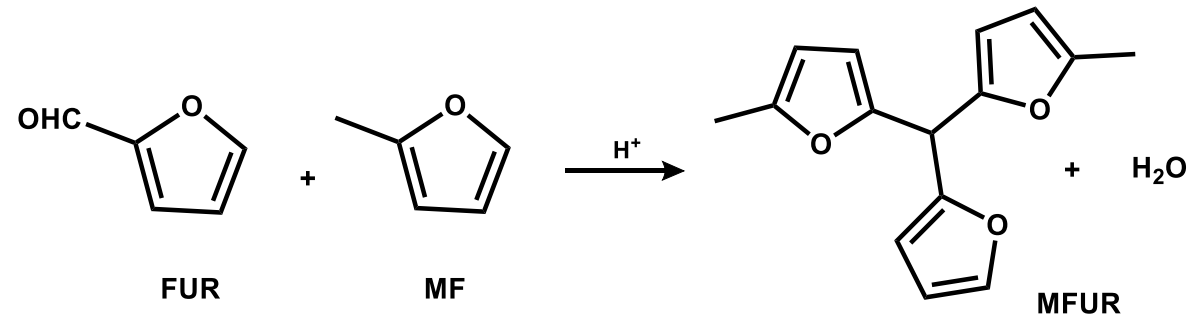

Scheme 3. Aldol condensation of furfural and 2-methylfuran.
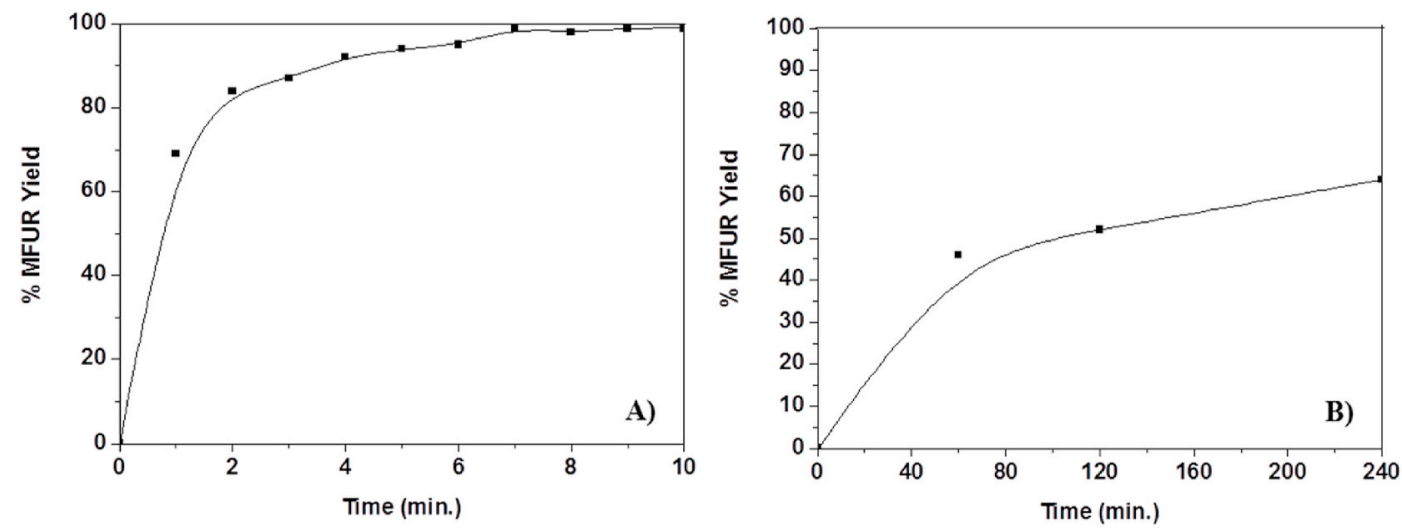

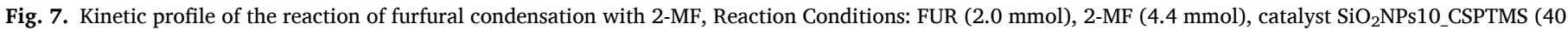
$\mathrm{mg}$ ); A) $65^{\circ} \mathrm{C}$, and B) $0{ }^{\circ} \mathrm{C}$.

using sulfonic acid functionalized coal fly ashes and the same reaction conditions, Table S1 [51]. These results show the potential of $\mathrm{SiO}_{2} \mathrm{NPs}_{10} \mathrm{CSPTMS}$, as solid acid catalysts for the preparation of $\mathrm{n}$-alkyl levulinates fuel additives. Furthermore, $\mathrm{SiO}_{2}$ NPs10_CSPTMS demonstrated to be a very stable catalyst in the esterification of LA with 1-propanol, Fig. $6 \mathrm{~B}$, with no loss of activity until the $10^{\text {th }}$ cycle $(>90 \%)$ which is excellent comparing with other sulfonic acid silica based catalysts [8] (Table S1, supplementary information). However, $\mathrm{SiO}_{2} \mathrm{NPs}_{100} \mathrm{CSPTMS}$ catalyst showed some deactivation after the $2^{\text {nd }}$ cycle although after that the stability was maintained constant until the $10^{\text {th }}$ cycle. The carbon and sulfur content determined by $\mathrm{AE}$, after the $10^{\text {th }}$ cycle demonstrated a significant leaching of $\mathrm{SO}_{3} \mathrm{H}$-aryl groups for $\mathrm{SiO}_{2} \mathrm{NPs}_{100} \mathrm{CSPTMS}$ (2.8 and $0.1 \mathrm{mmol} \mathrm{g}^{-1}$ of carbon and sulfur, respectively) during the reuses, justifying the loss of activity during the consecutive cycles.

The TOF values for $\mathrm{SiO}_{2} \mathrm{NPs}_{10}$ CSPTMS $\left(204-350 \mathrm{~h}^{-1}\right)$ are higher than those obtained for $\mathrm{SiO}_{2}$ NPs100_CSPTMS (181-196 $\mathrm{h}^{-1}$ ). Furthermore, decreasing the alcohol molecular weight decreases TOF values even for the catalyst with the best performance, $\mathrm{SiO}_{2} \mathrm{NPs}_{10} \mathrm{CSPTMS}$.

\subsection{Catalytic performance in the condensation reaction of furfural with 2-methylfuran}

The $\mathrm{SiO}_{2} \mathrm{NPs} 100$ CSPTMS and $\mathrm{SiO}_{2} \mathrm{NPs} 10$ CSPTMS catalysts were tested in the condensation reaction between FUR and 2-MF (Scheme 3). Following the reaction conditions adapted from literature and reported by Bell et al. [33], the condensation reaction between FUR and 2-MF was performed under environmentally friendly conditions and resulted in the formation of 5,5'-bis(2-methylfuranyl)fur-an-2-ylmethane (MFUR) in very good yields.

Following the reported by Bell et al. under solvent-free conditions, the desired condensation product MFUR was prepared in high yield ( $\geq 98 \%$ ) with concomitant complete conversion of furfural, at $65{ }^{\circ} \mathrm{C}$ and after $2 \mathrm{~h}$ reaction, using both $\mathrm{SiO}_{2} \mathrm{NPs} 100$ CSPTMS and $\mathrm{SiO}_{2} \mathrm{NPs}_{10}$ CSPTMS. Moreover, $\mathrm{SiO}_{2} \mathrm{NPs}_{10}$ CSPTMS was able to convert all the furfural to produce selectively MFUR in $10 \mathrm{~min}$ (Fig. 7A). a lower

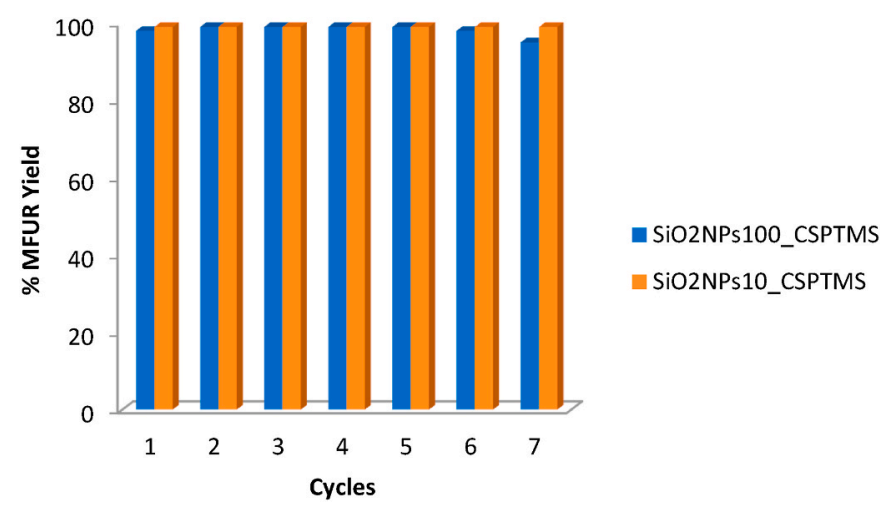

Fig. 8. Catalysts reusability of SiO2NPs100_CSPTMS (orange) and SiO2NPs10_CSPTMS (blue). (For interpretation of the references to colour in this figure legend, the reader is referred to the Web version of this article.)

reaction time than the obtained by other sulfonic acid-based catalysts prepared by post-grafting methodology [31], which demonstrates the excellent catalytic performance of this catalyst to promote aldol condensation of FUR into MFUR. The MFUR yield was determined by ${ }^{1} \mathrm{H}$ NMR (Fig. S2, supplementary information). Moreover the reaction was performed at $0{ }^{\circ} \mathrm{C}$, in the presence of and $\mathrm{SiO}_{2} \mathrm{NPs}_{10} \mathrm{CSPTMS}$ and $52 \%$ yield was achieved after $2 \mathrm{~h}$, Fig. 7B), increasing to $64 \%$ after $4 \mathrm{~h}$ reaction.

The reusability of both catalysts $\mathrm{SiO}_{2} \mathrm{NPs} 100$ CSPTMS and $\mathrm{SiO}_{2} \mathrm{NPs}_{10}$ CSPTMS was also explored (Fig. 8). The catalysts were isolated by filtration after the $1^{\text {st }}$ cycle condensation reaction at $65^{\circ} \mathrm{C}$ for 2 $\mathrm{h}$ and reused in 6 more consecutive cycles. No changes were observed in MFUR yield remaining close to $100 \%$ showing that the reactivity and stability of both catalysts was maintained constant without loss of activity. 


\section{Conclusions}

This work presents the preparation of efficient nanocatalysts based on silica nanoparticles. The sulfonic acid aryl- $\mathrm{SiO}_{2} \mathrm{NPs}$ catalysts were prepared through two different cost-effective post-grafting methodologies using distinct nano-sized silica $(\sim 10$ and $100 \mathrm{~nm})$. The direct organosilylation with CSPTMS and the two-step condensation of $\mathrm{SiO}_{2} \mathrm{NPs}$ with $\mathrm{BnOH}$ followed by chlorosulfonation with $\mathrm{ClSO}_{3} \mathrm{H}$ allowed to successfully introduce the desired sulfonic acid moieties. The chemical composition of the $\mathrm{SO}_{3} \mathrm{H}$-aryl- $\mathrm{SiO}_{2} \mathrm{NPs}$ was obtained by AE and XPS (by the presence of carbon and sulfur) and the structural characterization, acquired by FTIR, identified the characteristic vibrational modes of the sulfonic acid aryl groups, confirming the successful functionalization procedures.

The catalytic performance of all the as-prepared $\mathrm{SO}_{3} \mathrm{H}$-aryl- $\mathrm{SiO}_{2} \mathrm{NPs}$ was evaluated for the esterification reaction of different size chain and degree of unsaturation carboxylic acids. All the nanocatalysts exhibited high activity achieving complete conversion for the lauric, linoleic, oleic, palmitic and stearic methyl esters, using the $\mathrm{SiO}_{2} \mathrm{NPs}_{10} \mathrm{CSPTMS}$ and $\mathrm{SiO}_{2} \mathrm{NPs} 100$ CSPTMS as catalyst, indicating that in this case the catalytic results are independent of the carboxylic acid used and no diffusion limitation and reduced accessibility of acid sites were observed as previously described by other authors, showing the potential of these materials to be use as catalysts in esterification of any type of FFA for biodiesel production.

Furthermore, both $\mathrm{SiO}_{2} \mathrm{NPs}_{-} \mathrm{CSPTMS}$ nanomaterials were used in the esterification reaction of LA in presence of different alcohols, 1-butanol and 1-propanol, showing high yields (100\%) after $2 \mathrm{~h}$, good selectivity and reusability. For instance, $83.2 \%$ yield of PL was obtained after 10 consecutives catalytic cycles using $\mathrm{SiO}_{2} \mathrm{NPs} 10 \_\mathrm{CSPTMS}$ at $120^{\circ} \mathrm{C}$. The same catalysts have shown to be efficient to produce 5,5'-bis(2-methylfuranyl)furan-2-ylmethane under solvent-free conditions. Both catalysts resulted in almost complete conversion even at short reaction time and at $65{ }^{\circ} \mathrm{C}$ of temperature. After completion of seven cycles both catalysts continue to show high reactivity and stability.

In summary, we proved to prepare versatile $\mathrm{SO}_{3} \mathrm{H}$-aryl- $-\mathrm{SiO}_{2} \mathrm{NPs}$ based nanocatalysts as alternative to the conventional homogeneous catalyst and to costly and complex synthesized heterogeneous catalysts overcoming the typical problems of liquid acid catalysts and addressing the challenges of other heterogeneous catalysts including diffusion limitations and reduced accessibility to the acid sites. These catalysts were highly active and stable not only in the esterification reaction of FFA and LA but also in condensation reaction of furan derivatives highlighting their versatility and demonstrating the potential of these catalysts for the production of biodiesel and fuel additives.

\section{Acknowledgements}

This work was funded by Fundação para a Ciência e a Tecnologia - Ministério da Ciência, Tecnologia e Ensino Superior (FCT/MCTES, Portugal) through national funds, projects: UID/QUI/50006/2019, PTDC/BII-BIO/30884/2017 and PTDC/QUI-QIN/29778/2017. AFP thanks FCT/MCTES for their work contract (in the scope of the framework contract foreseen in the numbers 4, 5 and 6 of the article 23, of the Decree-Law 57/2016, of August 29, changed by Law 57/2017, of July 19) supported by national funds (OE).

\section{Appendix A. Supplementary data}

Supplementary data to this article can be found online at https://doi. org/10.1016/j.biombioe.2020.105936.

\section{References}

[1] A. Abbaszaadeh, B. Ghobadian, M.R. Omidkhah, G. Najafi, Energy Convers. Manag. 63 (2012) 138-148.

[2] M. Chai, Q. Tu, M. Lu, Y.J. Yang, Fuel Process. Technol. 125 (2014) 106-113.

[3] A.F. Lee, J.A. Bennett, J.C. Manayil, K. Wilson, Chem. Soc. Rev. 43 (2014) 7887-7916.

[4] T. Parangi, M.K. Mishra, Comments Mod. Chem. 40 (2020) 176-216.

[5] F.G. Cirujano, A. Corma, F.X. Llabrés i Xamena, Chem. Eng. Sci. 124 (2015) 52-60.

[6] M.M. Zainol, N.A.S. Amin, M. Asmadi, N.A.S. Ramli, BioEnergy Research 12 (2019) 359-369.

[7] J. Yang, G. Li, L. Zhang, S. Zhang, Catalysts 8 (2018) 14.

[8] K.C. Badgujar, V.C. Badgujar, B.M. Bhanage, Fuel Process. Technol. 197 (2020) 106213.

[9] Z. Wang, T. Lei, L. Liu, J. Zhu, X. He, Z. Li, BioResources 7 (2012) 11.

[10] D.R. Fernandes, A.S. Rocha, E.F. Mai, C.J.A. Mota, V. Teixeira Da Silva, Appl. Catal. Gen. (2012) 425-426, 199-204.

[11] D.M. Dal Pozzo, J.A. Azevedo Dos Santos, E.S. Júnior, R.F. Santos, A. Feiden, S. N. Melegari De Souza, I. Burgardt, RSC Adv. 9 (2019) 4900-4907.

[12] M.A. Tejero, E. Ramírez, C. Fité, J. Tejero, F. Cunill, Appl. Catal. Gen. 517 (2016) 56-66.

[13] J. Fu, L. Chen, P. Lv, L. Yang, Z. Yuan, Fuel 154 (2015) 1-8.

[14] J.A. Melero, G. Morales, J. Iglesias, M. Paniagua, B. Hernández, S. Penedo, Appl. Catal. Gen. 466 (2013) 116-122.

[15] S. An, D. Song, B. Lu, X. Yang, Y.H. Guo, Chem. Eur J. 21 (2015) 10786-10798.

[16] R. Maggi, N.R. Shiju, V. Santacroce, G. Maestri, F. Bigi, G. Rothenberg, Beilstein J. Org. Chem. 12 (2016) 2173-2180.

[17] N.A.S. Ramli, N.I. Hisham, N.A.S. Amin, Sains Malays. 47 (2018) 1131-1138.

[18] R. Zhong, B.F. Sels, Appl. Catal., B 236 (2018) 518-545.

[19] P. Hesemann, Curr. Opin. Green Sustain. Chem. 10 (2018) 21-26.

[20] W. Xie, C. Qi, H. Wang, Y. Liu, Fuel Process. Technol. 119 (2014) 98-104.

[21] I.K. Mbaraka, K.J. McGuire, B.H. Shanks, Ind. Eng. Chem. Res. 45 (2006) 3022-3028.

[22] J.A. Melero, L.F. Bautista, G. Morales, J. Iglesias, R. Sánchez-Vázquez, Chem. Eng. J. 161 (2010) 323-331.

[23] J.A. Melero, G.D. Stucky, R. van Griekena, G. Morales, J. Mater. Chem. 12 (2002) 1664-1670.

[24] I.K. Mbaraka, D.R. Radu, V.S.Y. Lin, B.H. Shanks, J. Catal. 219 (2003) 329-336.

[25] J. Dhainaut, J.P. Dacquin, A.F. Lee, K. Wilson, Green Chem. 12 (2010) 296-303.

[26] C. Pirez, J. Caderon, J. Dacquin, A.F. Lee, K. Wilson, ACS Catal. (2012) 1607-1614.

[27] A.F. Lee, J.A. Bennett, J.C. Manayil, K. Wilson, Chem. Soc. Rev. 43 (2014) 7887-7916.

[28] R. Mariscal, P. Maireles-Torres, M. Ojeda, I. Sádaba, M. López Granados, Energy Environ. Sci. 9 (2016) 1144-1189.

[29] J. Cueto, V. Korobka, L. Faba, E. Díaz, S. Ordóñez, ACS Sustain. Chem. Eng. 8 (2020) 4371-4383.

[30] S.S. Li, N. Li, G.Y. Li, L. Li, A.Q. Wang, Y. Cong, X.D. Wang, T. Zhang, Green Chem. 17 (2015) 3644-3652.

[31] M.N. Gebresillase, R. Shavi, J.G. Seo, Green Chem. 20 (2018) 5133-5146.

[32] G. Li, N. Li, Z. Wang, C. Li, A. Wang, X. Wang, Y. Cong, T. Zhang, ChemSusChem 5 (2012) 1958-1966.

[33] M. Balakrishnan, E.R. Sacia, A.T. Bell, ChemSusChem 7 (2014) 1078-1085.

[34] M.M. Aboelhassan, A.F. Peixoto, C. Freire, New J. Chem. 41 (2017) 3595-3605.

[35] T.V. Pinto, P. Costa, C.M. Sousa, C.A.D. Sousa, A. Monteiro, C. Pereira, O.S.G. P. Soares, C.S.M. Silva, M.F.R. Pereira, P.J. Coelho, C. Freire, ACS Appl. Mater. Interfaces 8 (2016) 7221-7231.

[36] T.V. Pinto, C.M. Sousa, C.A.D. Sousa, M.M. Aboelhassan, A.F. Peixoto, C. Pereira, P. J. Coelho, C. Freire, Dalton Trans. 46 (2017) 9076-9087.

[37] C. Pereira, C. Alves, A. Monteiro, C. Magén, A.M. Pereira, A. Ibarra, M.R. Ibarra, P. B. Tavares, J.P. Araújo, G. Blanco, J.M. Pintado, A.P. Carvalho, J. Pires, M.F. R. Pereira, C. Freire, ACS Appl. Mater. Interfaces 3 (2011) 2289-2299.

[38] Q. Guan, Y. Li, Y. Chen, Y. Shi, J. Gu, B. Li, R. Miao, Q. Chen, P. Ning, RSC Adv. 7 (2017) 7250-7258.

[39] L.H. Tamborini, M.E. Casco, M.P. Militello, J. Silvestre-Albero, C.A. Barbero, D. F. Acevedo, Fuel Process. Technol. 149 (2016) 209-217.

[40] Z. Yao, M. Cui, Z. Zhang, L. Wu, T. Xu, Polymers (Basel) 9 (2017) 631-645.

[41] F. Breu, S. Guggenbichler, J. Wollmann, Structure Determination of Organic Compounds - Tables of Spectral Data, fourth ed., Springer-Verlag, Berlin, Germany, 2009.

[42] S. Besselmann, E. Löffler, M. Muhler, J. Mol. Catal. Chem. 162 (2000) 401-411.

[43] X. Wang, S. Cheng, J.C.C. Chan, J.C.H. Chao, Microporous Mesoporous Mater. 96 (2006) 321-330.

[44] S.M. Silva, A.F. Peixoto, C. Freire, Appl. Catal. Gen. 568 (2018) 221-230.

[45] S.M. Silva, A.F. Peixoto, C. Freire, Renew. Energy 146 (2020) 2416-2429.

[46] Y. Liu, E. Lotero, J.G. Goodwin, J. Catal. 243 (2006) 221-228.

[47] A. Osatiashtiani, L.J. Durndell, J.C. Manayil, A.F. Lee, K. Wilson, Green Chem. 18 (2016) 5529-5535.

[48] S. Santos, L. Nobre, J. Gomes, J. Puna, R. Quinta-Ferreira, J. Bordado, Energies 12 (2019) 4670-4679.

[49] J.P. Dacquin, A.F. Lee, C. Pirez, K. Wilson, Chem. Commun. 48 (2012) 212-214.

[50] A.A. Kiss, A.C. Dimian, G. Rothenberg, Adv. Synth. Catal. 348 (2006) 75-81.

[51] A.F. Peixoto, S.M. Silva, P. Costa, A.C. Santos, B. Valentim, J.M. Lázaro-Martínez, C. Freire, Catal. Today 357 (2019) 74-83. 